\title{
Large Zeolite Manufacturer in China Optimizes Production
}

\author{
The company has been manufacturing synthetic zeolite powders since 2002. Among its \\ customers, the Chinese manufacturer has earned a good reputation in the areas of air separation \\ and purification, petrochemical and refining, and the painting and coating industry. In close \\ cooperation with universities products are improved so that specific customer requirements can \\ be met. Production is also constantly being updated and optimized. In this context, the company \\ has now chosen to work with Eirich for the production of small granulates.
}

Zeolites are aluminosilicates that have a structure of uniformly shaped pores or channels, in which substances can be adsorbed. In the case of naturally occurring zeolites, this is usually water, which can be driven out of the pores by heating up the material. The product can then be used as an extremely effective drying agent, for example for gases or organic solvents. Synthetic zeolites with defined pore sizes have been manufactured since around 1960. Since these can only adsorb molecules that are smaller than the pores, they are known as molecular sieves. The internal surface areas of these zeolites can exceed $1,000 \mathrm{~m}^{2}$ per gram, offering many different potential applications such as catalysts in the chemical industry.

For many applications, the zeolites which come in powder form - are mixed with special additives and transformed into a granulate form. Eirich mixers have proven themselves in many industries for mixing and granulating. Available in sizes from 11 to
$3000 \mathrm{l}$, these mixers only require a single moving mixing tool, which is known as the rotor. Depending on the task, the rotor can run at speeds up to more than $30 \mathrm{~m} / \mathrm{s}$. This makes it possible to generate high shear forces and distribute solids or liquids quickly. Varying the tools and speeds can have a considerable influence on the grain spectrum; granules with a $\mathrm{d}_{50}$ value ranging from $<100 \mu \mathrm{m}$ to more than $5 \mathrm{~mm}$ are possible, depending on the material.

In the customer's production, the two mixers in fully automatic operation replace six granulating drums, each of which had to be monitored and adjusted by workers. The short batch times and increased yield of good product proved to be advantageous, and significant energy savings were achieved overall. In addition to two mixers of type RV 16 (usable capacity of 900 liters / $1440 \mathrm{~kg}$, Figure 1), Eirich also supplied the screw feeders, balances and the control system. The new system was taken into opera-

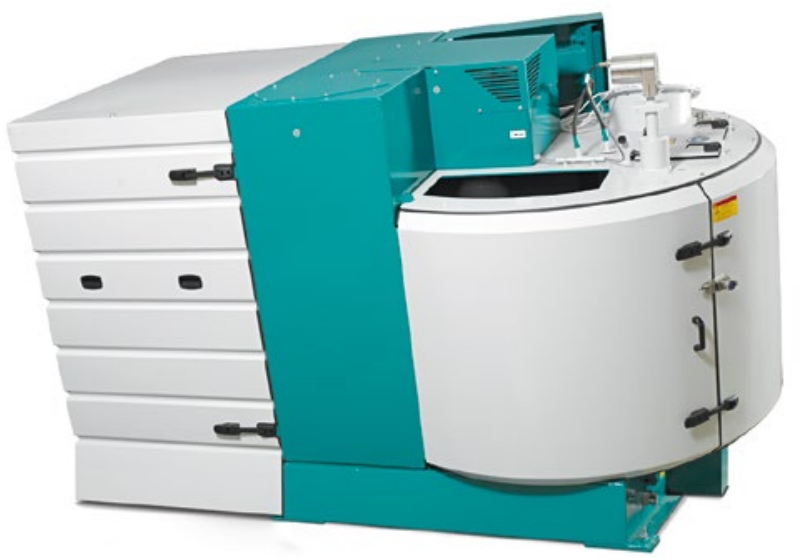

Figure 1 Mixer with a capacity of 900 liters (๑ Eirich)

\section{About Eirich}

The Eirich Group is a supplier of industrial mixing, granulating/pelletizing, drying and fine grinding machinery, systems and services. The group has its main strategic base at the corporate headquarters site in Hardheim, Germany. The company has core expertise in processes and techniques used for the preparation of free-flowing materials, slurry and sludge. The main fields of application for such technologies include for example ceramic and refractory materials, foundries, building materials such as concrete and plaster, battery pastes, fertilizers, glass and the processing of ores. The family-managed company was founded in 1863 and operates from twelve locations on five continents.

tion in the spring of 2020. It enables the manufacturer to supply customers with even better products.

Eirich advises its customers on solutions for mixing and granulating processes to deliver the best conditions for production at lower cost. Test centers are available at all locations around the world where processes can be optimized with the customers' own products.

Contact:

Maschinenfabrik Gustav Eirich GmbH \& Co KG, 74736 Hardheim, Germany, www.eirich.com/en/ 